\title{
THE ROLE OF HUMIC ACID IN THE CORROSION OF AZ31 MAGNESIUM ALLOY
}

\author{
Leoš DOSKOČIL, Jiří HONČ, Matěj BŘEZINA, Jaromír WASSERBAUER \\ Brno University of Technology, Faculty of Chemistry, Brno, Czech Republic, EU, doskocil@fch.vut.cz
}

https://doi.org/10.37904/nanocon.2021.4331

\begin{abstract}
Magnesium alloys used as sacrificial anodes can interact with humic acids (HAs) in soil and water environments. Therefore, these natural organic molecules can have an impact on the corrosion behaviour of magnesium materials. In this work, the aim was to investigate the effect of lignitic HA on the corrosion of AZ31 magnesium alloy in $3.5 \% \mathrm{NaCl}$ at different $\mathrm{pH}(5,7$ and 9). The results showed that $\mathrm{HA}$ increased the corrosion rate about four times at $\mathrm{pH} 7$, while it weakly decreased the corrosion rate at $\mathrm{pH} 5$ and 9 . The acceleration of corrosion is probably related to the depletion of $\mathrm{Mg}^{2+}$ ions by forming complexes with $\mathrm{HA}$ instead of producing $\mathrm{Mg}(\mathrm{OH}) 2$. The increase in corrosion resistance may be related to the reduced stability of the complexes and adsorption on the AZ31 alloy surface at $\mathrm{pH} 5$ and 9 . Surface analysis suggested that the presence of $\mathrm{HA}$ promotes the formation of $\mathrm{Mg}(\mathrm{OH})_{2}$ nanoparticles.
\end{abstract}

Keywords: Corrosion, AZ31 magnesium alloy, humic acid

\section{INTRODUCTION}

Magnesium is a lightweight metal with superior strength to weight ratio, high specific stiffness, electromagnetic shielding property and high thermal conductivity [1]. These features make it a great choice for various applications in the automotive industry, aeronautics, electronics, biodegradable medical implants etc. [1,2]. Unfortunately, a poor corrosion resistance is the biggest limiting factor for its wider use. This disadvantage can be overcome to some extent by the preparation of magnesium alloys, which most often contain alloying elements such as aluminium, zinc, manganese. For example, the popular magnesium alloy AZ31 is made up of about $3 \%$ aluminium and about $1 \%$ zinc [1].

High electrochemical activity and high susceptibility to corrosion in many environments predetermine magnesium and its alloys to be used as a sacrificial anode in cathodic protection of steel structures such as of oil and gas pipelines, oil drilling platforms cables, heat exchangers, aircraft, ships (ship hulls) and bridges [1].

Magnesium anodes are of two generic types, Mg-Mn and Mg-Al-Zn. Both alloy systems have a high driving voltage a therefore find application in high resistivity environments such as soil and fresh, or brackish waters. Because magnesium is nontoxic, its use is permissible in potable water systems wherein the conductivity is low [3].

As far as the authors know, very little is known about the corrosion of magnesium and its alloys in the soil. The literature commonly states that magnesium is quite resistant to corrosion in soil. The presence of calcium and magnesium salts in most soils tends to inhibit corrosion, but the corrosivity is different in different kinds of soil [4].

Humic substances are an important component of soils, which can have an impact on the corrosion behavior of materials. Previous publications have shown that humic substances have an impact on the corrosion process of steel, galvanized steel and brass [5,6]. However, the effect of humic substances on magnesium corrosion is not known in soil or water environment. 
Humic substances are the heterogeneous mixture of organic molecules which are traditionally divided based on their alkaline and acid solubility into three classes: humic acid (HA), fulvic acid, and humin [7]. HAs are characterized by high molecular weight and a high content of O-functional groups such as carboxylic and hydroxyl groups. HA occurs not only in water and soil but also in peat, coal and leonardite, whereas their chemical-physical properties may differ from each other depending on their origin. An increase in the content of HAs (generally organic matter) in soil and water can be expected due to the growing interest in green agriculture and other interventions of human to the natural environment [7]. In connection with this fact, the interactions of organic substances with magnesium anode (generally metal materials) will become increasingly important. Therefore, the investigation of changes in the corrosion resistance/mechanisms of magnesium materials in the presence of HAs may be a desirable challenge for corrosion research.

Corrosion of magnesium and its alloys in the presence of HAs can also have an impact on the presence of inorganic ions in the corrosive environment. Corrosion of the magnesium sacrificial anode results in the release of predominantly magnesium ions as well as aluminum or zinc ions due to oxidation of the anode.

It is also conceivable that HAs could be involved in the formation of magnesium hydroxide nanoparticles, which form on the surface of the magnesium anode during corrosion.

Pankratov et al. [8] recently discovered that magnetic nanoparticles of iron oxides can be stabilized by HAs and suggested that the nanoparticles can be formed also during corrosion of iron in contact with soil.

The aim of this work is to determine the effect of lignite HA on the corrosion of AZ31 alloy in the environment of $3.5 \% \mathrm{NaCl}$ at different $\mathrm{pH}(5,7$ and 9$)$.

\section{EXPERMENTAL}

HA was isolated from South Moravian lignite, which was obtained from the locality Mikulčice, Czech Republic. Lignitic HA was extracted using a modified procedure recommended by the International Humic Substances Society. Briefly, air-dried lignite was demineralized with $0.1 \mathrm{~mol} / \mathrm{l}$ hydrochloric acid and the suspension was then washed with deionized water until an almost neutral $\mathrm{pH}$ was achieved. Suspension was shaken overnight with $0.1 \mathrm{~mol} / \mathrm{l} \mathrm{NaOH}$ and $0.1 \mathrm{~mol} / / \mathrm{Na}_{4} \mathrm{P}_{2} \mathrm{O}_{7}$. After centrifugation, $\mathrm{HA}$ was precipitated from the supernatant by means of acidification to $\mathrm{pH}<2$ with $6 \mathrm{~mol} / \mathrm{l} \mathrm{HCl}$, and further separated by centrifugation. Precipitated $\mathrm{HA}$ was purified and dialysed using a Spectra/Por cellulose membrane $(1 \mathrm{kDa})$ until the free chloride ions were washed out and the purified lignite HA was finally freeze-dried.

A stock solution of $100 \mathrm{mg} / \mathrm{l} \mathrm{HA}$ was prepared by dissolving in $0.1 \mathrm{~mol} / \mathrm{l} \mathrm{NaOH}$ containing $3.5 \% \mathrm{NaCl}$. Three fractions of HAs were obtained from the stock solution by lowering the $\mathrm{pH}$ to 9,7 and 5 by sequential addition of $\mathrm{HCl}$ with stirring. The precipitated $\mathrm{HA}$ was centrifuged, and the supernatant was filtered through a $0.45 \mu \mathrm{m}$ filter. The obtained $\mathrm{pH}$-fractionated $\mathrm{HAs}$ were stored in a refrigerator and used for corrosion tests within one week.

AZ31 magnesium alloy samples $(20 \times 20 \times 6 \mathrm{~mm})$ were used for corrosion tests. Their chemical composition was determined using Glow-Discharge Optical Emission Spectroscopy (GDOES); $3.60 \% \mathrm{Al}, 1.34 \% \mathrm{Zn}, 0.28$ $\mathrm{Mn}, 0.03 \mathrm{Si}, 0.002 \mathrm{Fe}$ and $0.01 \mathrm{Sn}$. The samples of AZ31 alloy were ground using 320 and $1200 \mathrm{SiC}$ grit abrasive papers, washed in distilled water and isopropyl alcohol and then dried by hot air.

Total organic carbon (TOC) was determined by accredited testing laboratory LABTECH using a Shimadzu TOC 5000A analyzer according to Czech technical standard ČSN EN 1484.

The UV/Vis absorption spectra of $\mathrm{HA}$ and $\mathrm{pH}$-fractionated $\mathrm{HAs}$ at a concentration of $5 \mathrm{mg} / \mathrm{l} \mathrm{C}$ were recorded on Hitachi U-3900H double beam UV/Vis spectrometer (Hitachi, Tokyo, Japan) in the spectral range between 200 and $800 \mathrm{~nm}$. Sodium borate buffer $\left(1 \mathrm{~mol} / / \mathrm{H}_{3} \mathrm{BO}_{3}, 0.25 \mathrm{~mol} / \mathrm{l} \mathrm{NaOH}\right)$ was used as a solvent of the fractions and as well as a blank solution. 
The Attenuated Total Reflectance (ATR-FTIR) technique was used for a structural characterization of organic substances. Fourier transform infrared (FTIR) spectra of the substances were recorded on Nicolet iS50 spectrometer (Thermo Fisher Scientific, Waltham, MA, USA) using the Attenuated Total Reflectance (ATR) measuring technique (single reflection built in diamond ATR crystal). All measurements were taken in the spectral range $4000-400 \mathrm{~cm}^{-1}$ at $4 \mathrm{~cm}^{-1}$ resolutions as an average of 256 scans. A background spectrum was collected from the clean dry surface of the ATR crystal in an ambient atmosphere.

The short-time potentiodynamic measurements were performed in $3.5 \% \mathrm{NaCl}$ solution with and without $\mathrm{pH}$ fractionated HAs at laboratory temperature using the Bio-Logic VSP-300 potentiostat (BioLogic, SeyssinetPariset, France). The corrosion solutions contained 0 and $15 \mathrm{mg} / \mathrm{l} \mathrm{C}$ of $\mathrm{pH}$-fractionated HAs. Measured samples with exposed area of $1 \mathrm{~cm}^{2}$ served as a working electrode. Saturated calomel electrode (SCE) was used as a reference electrode and Pt wire as a counter-electrode. Open circuit potential (OCP) variations with time were recorded up to 10 min of exposure. Afterward, Tafel plot was obtained by carrying out partial potentiodynamic polarization in the potential range from $-200 \mathrm{mV}$ to $250 \mathrm{mV}$ from OCP at the potential scan rate of $1 \mathrm{mV} / \mathrm{s}$.

Surface analysis of the samples after corrosion was performed using scanning electron microscopy (SEM; JEOL JSM-7600F, Tokyo, Japan). Energy-dispersive X-ray spectroscopy (EDS, model OXFORD INSTRUMENTS X-MAX $80 \mathrm{~mm}^{2}$ ) was used to examine the surface of the samples after electrochemical testing to specify the character of the corrosion products. Process of Au sputtering was used to prevent unfavorable sample conductivity.

\section{RESULTS AND DISCUSSION}

TOC analysis showed that all three fractions of HA contained $30 \mathrm{mg} / \mathrm{l}$ of carbon, whereas the starting HA before fractionation contained $50 \mathrm{mg} / \mathrm{l}$ of carbon. $\mathrm{HA}$ and its fractions soluble at $\mathrm{pH} 5,7$ and 9 were characterized using UV-Vis spectrometry and FTIR spectrometry. The UV-Vis absorbance spectra (not shown) were featureless and without the presence of any indication of a maximum and/or a minimum. The absorbance values decreased exponentially with increasing acquisition wavelength. Absorbance ratios $\mathrm{E}_{\mathrm{ET} / \mathrm{Bz}}$ and $E_{2 / 4}$ were calculated. The $E_{E T / B z}$ ratio (the ratio of absorbance at $253 \mathrm{~nm}$ to that $220 \mathrm{~nm}$ ) is higher for compounds in which the aromatic structural units are predominantly substituted with oxygen-containing functional groups, whereas lower values are associated with aliphatic substituents. The $E_{2 / 4}$ ratio (the ratio of absorbance at $265 \mathrm{~nm}$ to that $465 \mathrm{~nm}$ ) indicates the molecular size of the molecules and its aromaticity; the higher $\mathrm{E}_{2 / 4}$ ratio, the smaller size molecular size and the lower aromaticity. The $\mathrm{pH}$-fractionated HAs were very similar to each other ( $\mathrm{E}_{\mathrm{ET} / \mathrm{Bz}}$ and $\mathrm{E}_{2 / 4}$ were about 0.90 and 7.81, resp.), but different from the original $\mathrm{HA}$ ( $\mathrm{E}_{\mathrm{ET} / \mathrm{Bz}}$ and $E_{2 / 4}$ were 0.87 and 6.24, resp.). The results suggest that the fractionated HAs are composed of smaller molecules with lower aromaticity, and richer in oxygen functional groups.

FTIR spectra of HA and its fractions were very similar (not shown). They contained aliphatic groups (2905 and $2840 \mathrm{~cm}^{-1}$ ), including methyl and methylene groups. These groups were also confirmed by the deformation band $\left(1457 \mathrm{~cm}^{-1}\right)$. The bands at 1564 and $1369 \mathrm{~cm}^{-1}$ can be attributed to aromatic substances and methyl groups bound to aromatics, respectively. These bands can also be related to carboxylates. The presence of carboxyl groups was indicated by a band at $1700 \mathrm{~cm}^{-1}$. Spectra also contained aryl ether compounds (1262 $\mathrm{cm}^{-1}$ ), phenols and ethers $\left(1198\right.$ and $\left.1154 \mathrm{~cm}^{-1}\right)$, alcohols (1094 and $\left.1037 \mathrm{~cm}^{-1}\right)$. Out-of-plane C-H deformation bands were found in the $900-700 \mathrm{~cm}^{-1}$ region.

Potentiodynamic polarization was performed in $3.5 \% \mathrm{NaCl}$ medium with $15 \mathrm{mg} / \mathrm{l}$ carbon of $\mathrm{pH}$-fractionated HAs and in the absence of these HAs. All corrosion solutions were tested at three different pHs (5, 7 and 9). The potentiodynamic curves are shown in Figure 1 and the quantified values (corrosion current density icor and corrosion potential $E_{\text {cor) }}$ are given in Table 1. The determined values should be considered rather as indicative, because the obtained polarization curves do not exhibit conditions for Tafel analysis. As a result, 
Tafel fitting of data was only performed from the cathodic branch. However, a comparison of the position and shape of the polarization curves with the determined parameters ( $E_{c o r}$ and $\left.i_{c o r}\right)$ shows that there are no mutual contradictions. The corrosion current density of $\mathrm{AZ31}$ alloy in $3.5 \% \mathrm{NaCl}$ decreased with increasing $\mathrm{pH}$. This is in line with Pourbaix diagram and the literature $[9,10]$. The $i_{c o r}$ value is a measure of the corrosion rate; the higher the $\mathrm{i}_{\mathrm{c} o r}$, the higher the corrosion rate. Table $\mathbf{1}$ and Figure $\mathbf{1}$ show that AZ31 alloy had the lowest corrosion rate in $3.5 \% \mathrm{NaCl}$ at $\mathrm{pH}$ 9, whereas the highest corrosion rate was in $3.5 \% \mathrm{NaCl}$ at pH 5 . The corrosion current density decreased approximately sixfold by increasing the $\mathrm{pH}$ from 5 to 9 . The surface of the AZ31 alloy was slightly protected by the formation of a layer of $\mathrm{Mg}(\mathrm{OH})_{2}$ in an alkaline environment; the protective function of the layer decreased with lower $\mathrm{pH}$. In addition, the $\mathrm{Mg}(\mathrm{OH})_{2}$ layer is disrupted by the attack of chloride ions, which dissolve $\mathrm{Mg}(\mathrm{OH})_{2}$ into soluble $\mathrm{MgCl}_{2}[9,10]$. The corrosion potential of $\mathrm{E}_{\text {cor }}$ shifted slightly to a more positive value with increasing $\mathrm{pH}$, indicating better corrosion resistance of AZ31 alloy in the given environment.

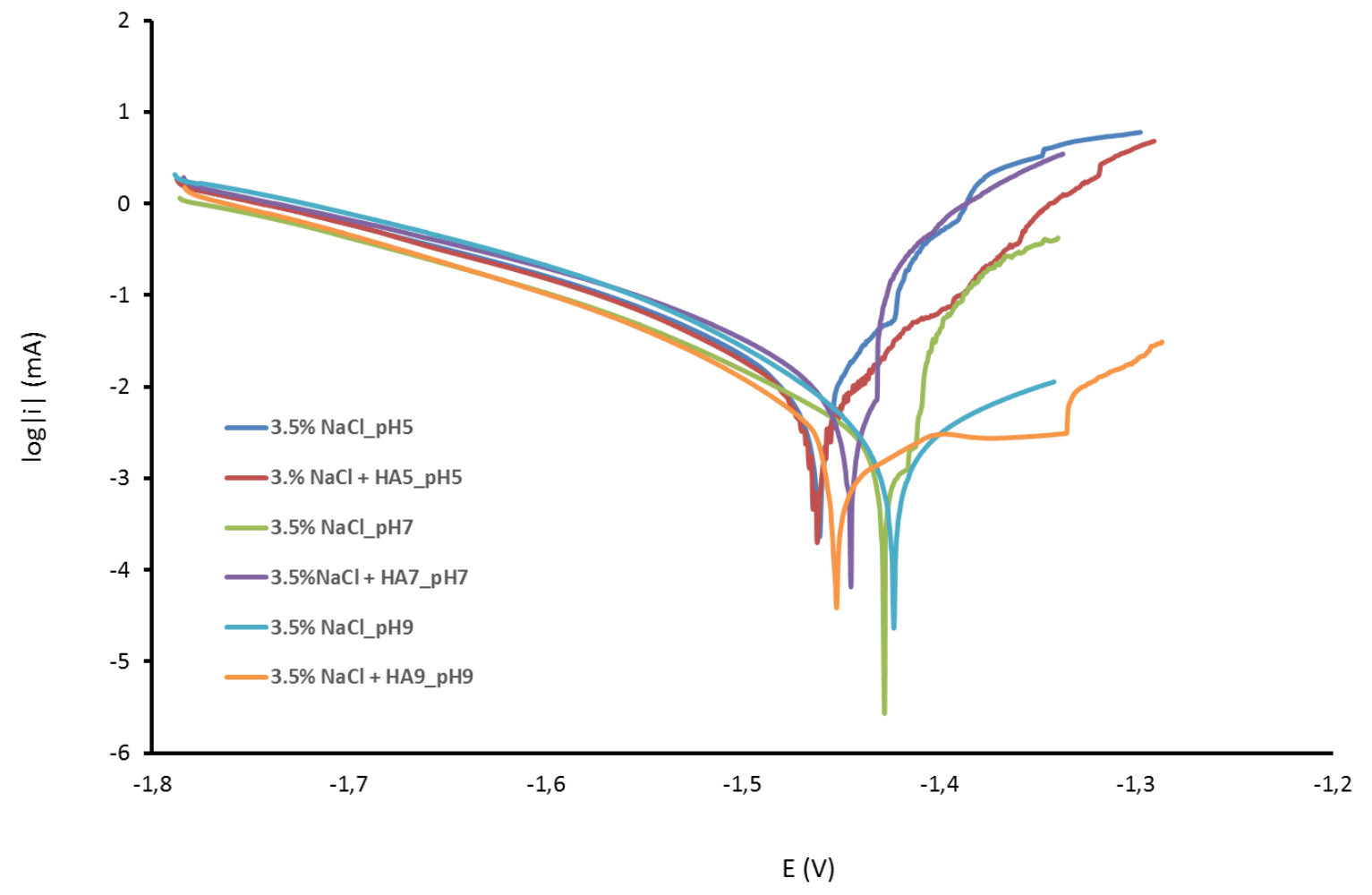

Figure 1 Potentiodynamic polarization curves of the $\mathrm{AZ31}$ alloy in $3.5 \% \mathrm{NaCl}$ with and without HAs.

The addition of $\mathrm{HA}$ to the $3.5 \% \mathrm{NaCl}$ solution led to a change in the corrosion resistance of the AZ31 alloy, as can be seen from the potentiodynamic curves. A significant change in corrosion resistance was found in the case of a corrosive environment with $\mathrm{pH}$ 7. The value of the corrosion current density increased four times after the addition of HA. This increase in corrosion rate may be related to the interaction of released magnesium ions with $\mathrm{HAs}$ to form complex compounds. This depletion of $\mathrm{Mg}^{2+}$ ions can lead to the formation of a poor layer of $\mathrm{Mg}(\mathrm{OH})_{2}$ on the surface. In contrast, the addition of $\mathrm{HA}$ to $3.5 \% \mathrm{NaCl}$ at pH 5 and 9 caused a slight decrease in the corrosion rate of the AZ31 alloy. The decrease in corrosion current density in alkaline media may be related to the a less willing interactions between $\mathrm{Mg}^{2+}$ ions and $\mathrm{HA}$ molecules to form stable complex compounds. In addition, a larger proportion of $\mathrm{HAs}$ can be adsorbed on the surface of $\mathrm{Mg}(\mathrm{OH})_{2}$, which is easily formed mainly in a strongly alkaline environment. The decrease in the corrosion rate in an acidic environment can be explained by the lower solubility of magnesium humates, which can be deposited on the surface of the AZ31 alloy. The layer formed can limit the access of aggressive ions to the surface and, as a result, slightly increase the corrosion resistance of the material. These observations are valid at least for short-term 
measurements. A more detailed analysis of the potentiodynamic curves shows that the change in $\mathrm{pH}$ and the addition of $\mathrm{HAs}$ to $3.5 \% \mathrm{NaCl}$ mainly have an impact on the shape of the anodic branch compared to the cathodic branch. A break in the anodic branches of the potentiodynamic curve indicates pitting, which is characteristic of corrosion in the presence of chlorides. The shape of the potentiodynamic curves suggests that the presence of $\mathrm{HAs}$ and $\mathrm{pH}$ do not affect the corrosion mechanism of $\mathrm{AZ} 31$ in $3.5 \% \mathrm{NaCl}$. The results also indicate that the corrosion behavior of $\mathrm{AZ31}$ alloy in $3.5 \% \mathrm{NaCl}$ is primarily controlled by $\mathrm{pH}$ and physicochemical properties of HAs. It should be noted that the chemical composition of the individual fractions of HAs is without significant differences. The more detailed role of HAs in corrosion will have to be studied in the future.

Table 1 Electrochemical parameters of potentiodynamic polarization.

\begin{tabular}{|c|c|c|c|}
\hline \multicolumn{2}{|c|}{ Corrosion solution } & $\mathrm{E}_{\text {cor }}(\mathrm{V}$ vs. SCE $)$ & $\mathrm{i}_{\mathrm{cor}}\left(\mu \mathrm{A} / \mathrm{cm}^{2}\right)$ \\
\hline \multirow{3}{*}{$\mathrm{pH} 5$} & $3.5 \% \mathrm{NaCl}$ & -1.46 & 18.4 \\
\cline { 2 - 4 } & $3.5 \% \mathrm{NaCl}+\mathrm{HA} 5$ & -1.46 & 17.7 \\
\hline \multirow{3}{*}{$\mathrm{pH} 7$} & $3.5 \% \mathrm{NaCl}$ & -1.43 & 4.5 \\
\hline \multirow{2}{*}{$\mathrm{pH} 9$} & $3.5 \% \mathrm{NaCl}+\mathrm{HA} 7$ & -1.45 & 18.1 \\
\cline { 2 - 4 } & $3.5 \% \mathrm{NaCl}$ & -1.42 & 3.4 \\
\hline
\end{tabular}
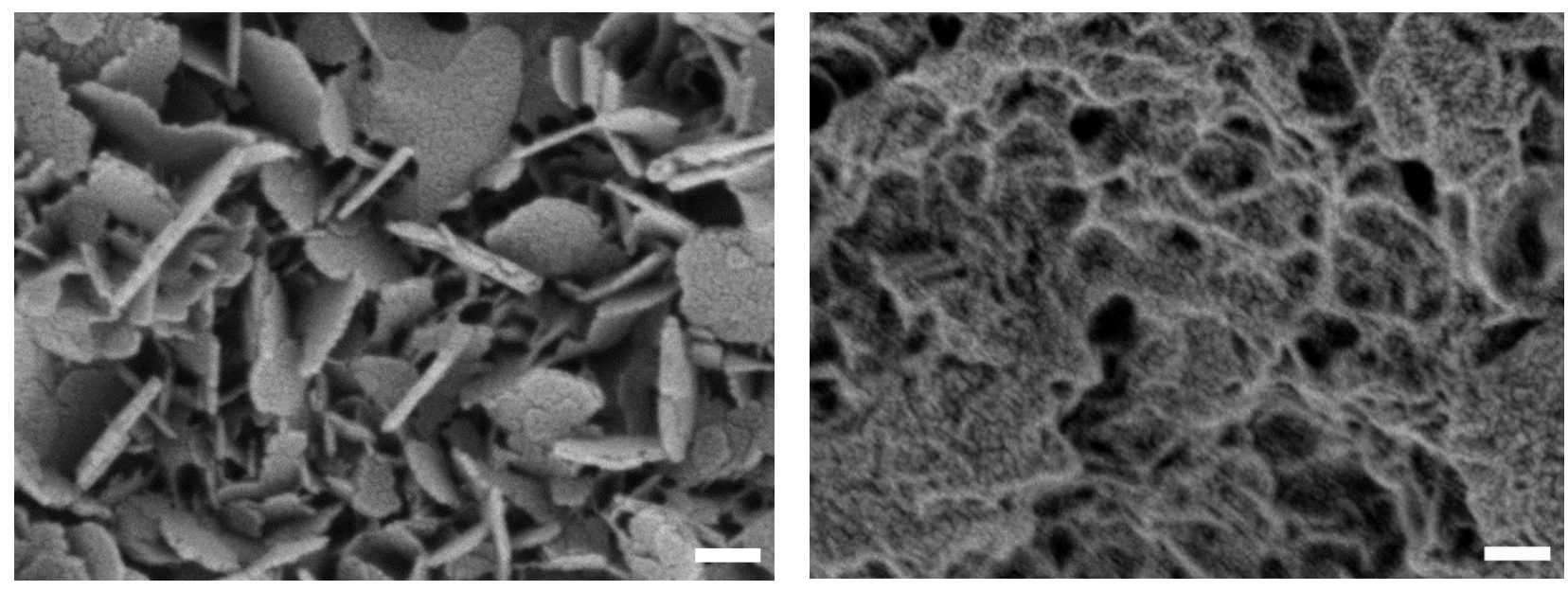

Figure 2 SEM images of AZ31 alloy surface after corrosion at $\mathrm{pH} 7$ in $3.5 \% \mathrm{NaCl}$ (left) and $3.5 \% \mathrm{NaCl}$ containing HA (right). Bar represents $100 \mathrm{~nm}$.

Surface analysis showed that the surface of the AZ31 alloy after corrosion is highly heterogeneous regardless of the presence of $\mathrm{HAs}$ and $\mathrm{pH}$. Figure 2 shows the characteristic surface of the samples after seven days of corrosion in $3.5 \% \mathrm{NaCl}$ medium with and without $\mathrm{HAs}$ at $\mathrm{pH}$ 7. The other samples are not presented as they did not differ significantly from each other. Particular emphasis was placed on detecting the presence of nanoparticles and/or nanoshape. Surface and elemental analysis revealed that the surface of the AZ31 alloy in $3.5 \% \mathrm{NaCl}$ was formed by $\mathrm{Mg}(\mathrm{OH})_{2}$ flat pieces with a thickness of about $40 \mathrm{~nm}$. The elemental composition of the corrosion products included approximately 69 at.\% $\mathrm{O}$ and 26 at.\% $\mathrm{Mg}$ and a minor occurrence of about 3 at. $\%$ aluminum (AZ31 alloy signal) and 2 at.\% $\mathrm{Cl}$. The surface of the samples, which

corroded in the environment containing HA molecules, was characterized by a network of flat pieces consisting probably of $\mathrm{Mg}(\mathrm{OH})_{2}$ and nanometer-sized spheres. Unfortunately, high quality images for samples corroded in HA environments could not be obtained due to difficulties associated with sample preparation for SEM 
analysis and during SEM analysis. As a result, it cannot be ruled out that the observed nanoparticles originate in gold that was deposited by the sputtering device. A typical elemental composition of corrosion products included about 61 at.\% O, 19 at.\% Mg and 18 at.\% C, and about 2 at.\% aluminum (AZ31 alloy signal). A significant proportion of carbon indicates the adsorption of $\mathrm{HAs}$ on the surface of $\mathrm{Mg}(\mathrm{OH})_{2}$ during corrosion.

\section{CONCLUSION}

The results indicate that $\mathrm{HA}$ can affect the corrosion resistance of $\mathrm{AZ31}$ alloy in $3.5 \% \mathrm{NaCl}$ depending on $\mathrm{pH}$. $\mathrm{HA}$ increased the corrosion rate about four times at $\mathrm{pH} 7$, while it weakly decreased the corrosion rate at $\mathrm{pH} 5$ and 9 . The acceleration of corrosion is probably related to the depletion of $\mathrm{Mg}^{2+}$ ions by forming complexes with $\mathrm{HA}$ instead of producing $\mathrm{Mg}(\mathrm{OH})_{2}$. This facilitates the attack of aggressive chloride ions with the magnesium alloy surface. The slight increase in corrosion resistance may be related to the reduced stability of the complexes and adsorption (mainly of HA molecules) on the AZ31 alloy surface at pH 5 and 9 . The effect of $\mathrm{HA}$ on the corrosion potential values was negligible. The shape of the potentiodynamic curves indicated that $\mathrm{HA}$ have no effect on the corrosion mechanism of AZ31 alloy in $3.5 \% \mathrm{NaCl}$ at different $\mathrm{pH}$. Surface analysis of AZ31 alloy after corrosion suggested that the presence of HA promotes the formation of $\mathrm{Mg}(\mathrm{OH})_{2}$

nanoparticles. Further research is needed to gain a deeper understanding of the role of HAs in the corrosion behavior of AZ31 alloys.

\section{ACKNOWLEDGEMENTS}

This work was supported by Specific University Research at FCH BUT, Project Nr. FCH-S-21-7553, Ministry of Education, Youth and Sports of the Czech Republic.

\section{REFERENCES}

[1] PATHAK, S., MENDON, S., BLANTON, M., RAWKINS, J.W. Magnesium-based sacrificial anode cathodic protection coatings (Mg-rich primers) for aluminium alloys. Metals. 2012, vol. 2, pp. 353-376.

[2] WASSERBAUER, J., BUCHTÍK, M., TKACZ, J., FINTOVÁ, S., MINDA, J., DOSKOČIL, L. Improvement of AZ91 Alloy Corrosion Properties by Duplex NI-P Coating Deposition. Materials, 2020, vol. 13, p. 1-17.

[3] CRUNDWELL, R.F. Sacrificial anodes. In: Shreir's Corrosion. Elsevier BV, 2010, pp. 2773.

[4] SONG, G.L., ATRENS, A. Corrosion Mechanisms of Magnesium Alloys. Advanced Engineering Materials. 1999, vol. 1, pp. 11-33.

[5] DICK, L.F.P., RODRIGUES, L.M. Influence of Humic Substances on the Corrosion of the API 5 LX65 Steel. Corrosion. 2006, vol. 62, pp. 35-45.

[6] SORIANO, C., ALFANTAZI, A. Corrosion behavior of galvanized steel due to typical soil organics. Construction and Building Materials. 2016, vol. 102, 904-912.

[7] DOSKOCIL, L., BURDIKOVÁ-SZEWIECZKOVA, J., ENEV. V., KALINA, L., WASSERBAUER, J. Spectral characterization and comparison of humic acids isolated from some European lignites. Fuel. 2018, vol. 213, pp. 123-132.

[8] PANKRATOV, D.A., ANUCHINA, M.M. Nature-inspired synthesis of magnetic non-stoichiometric $\mathrm{Fe}_{3} \mathrm{O}_{4}$ nanoparticles by oxidative in situ method in a humic medium. Materials Chemistry and Physics. 2019, vol. 231, pp. 216-224.

[9] MINDA, J., FINTOVÁ, S. HADZIMA, B., DOLEŽAL, P., HASOŇOVÁ, M., DOSKOČIL., WASSERBAUER, J. Electrochemical corrosion behavior of pure Mg processed by powder metallurgy. Coatings. 2021, vol. 11, pp. 986.

[10] THIRUMALAIKUMARASAMY, D., SHAMMUGAM, K., BALASUBRAMANIAN, V. Comparison of the corrosion behavior of AZ31B magnesium alloy under immersion test and potentiodynamic polarization test in $\mathrm{NaCl}$ solution. Journal of Magnesium and Alloys. 2014, vol. 2, pp. 36-49. 